AT-TAJDID: Jurnal Pendidikan Dan Pemikiran Islam

(p-ISSN: 2548-5784 |e-ISSN: 2549-2101)

Vol. (5) (01), (Januari-Juni) (2021), (62-73)

Doi: http://dx.doi.org/10.24127/att.v5i01.1556

\title{
KONSEP BUDAYA DALAM PANDANGAN ISLAM SEBAGAI SISTEM NILAI BUDAYA GLOBAL (ANALISIS TERHADAP TERHADAP PEMIKIRAN ALI AHMAD MADKUR)
}

\author{
R. Rofiani ${ }^{1}$ \\ Universitas Islam Negeri Sunan Gunung Djati Bandung ${ }^{1}$ \\ rofianiofi72@gmail.com ${ }^{1}$ \\ Nurwadjah Ahmad Eq ${ }^{2}$ \\ Universitas Islam Negeri Sunan Gunung Djati Bandung ${ }^{2}$ \\ nurwadjah@uinsgd.ac.id ${ }^{2}$ \\ Andewi Suhartini ${ }^{3}$ \\ Universitas Islam Negeri Sunan Gunung Djati Bandung ${ }^{3}$ \\ andewisuhartini@uinsgd.ac.id ${ }^{3}$
}

\begin{abstract}
ABSTRAK
Penelitian ini bertujuan untuk menganalisis kebudayaan dalam pandangan Islam sebagaimana yang dikemukakan oleh Ali Ahmad Madkur dalam kitab manhaj al-Tarbiyah fi al-Tashowwuri al-Islami, sebagai sistem nilai budaya global. Penelitian ini penting dilakukan karena tuntutan kebutuhan masyarakat secara global yang mengalami begitu banyak penurunan kualitas hidup akibat pesatnya perkembangan budaya barat atau budaya lain selain budaya Islam. Pemikiran Ali Ahmad Madkur memberikan wawasan penting terkait bagaimana kebudayaan dalam pandangan Islam ternyata mampu menjawab berbagai permasalahan hidup manusia, baik di bidang sosial, ekonomi, politik, Pendidikan, dan pengelolaan lingkungan hidup. Budaya Islam sebagai sistem nilai budaya dalam masyarakat diyakini dapat menjadi solusi bagi berbagai masalah dalam masyarakat selain kerusakan lingkungan dan ketidakadilan. Budaya Islam sebagai sistem nilai budaya memiliki karakteristik yang bersifat global dan diperlukan dalam kondisi masyarakat dunia saat ini.
\end{abstract}

Kata Kunci: : Budaya, Islam, Sistem nilai, global

\begin{abstract}
This study aims to analyze culture in the view of Islam as stated by Ali Ahmad Madkur in the manhaj alTarbiyah fi al-Tashowwuri al-Islami, as a global cultural value system. This research is important to do because of the demands of society's needs globally which have experienced so much decline in the quality of life due to the rapid development of western culture or cultures other than Islamic culture. Ali Ahmad Madkur's thoughts provide important insights related to how culture in the view of Islam is able to answer various problems of human life, both in the social, economic, political, education and environmental
\end{abstract}

Copyright (C) 2020, Universitas Muhammadiyah Metro| 62 
management fields. Islamic culture as a system of cultural values in society is believed to be a solution to various problems in society besides environmental damage and injustice. Islamic culture as a system of cultural values has global characteristics and is needed in the current conditions of the world community.

Keywords: Culture, Islam, value system, global

\section{A. PENDAHULUAN}

Kebudayaan telah didefinisikan oleh banyak pakar, di antaranya dikemukakan oleh

Koentjaraningrat (Koentjaraningrat,1980) yang mengutip pendapat Claude Kluckhohn bahwa kebudayaan adalah seluruh ide, gagasan, dan tindakan manusia dalam rangka memenuhi kebutuhan hidup sehari-hari melalui proses belajar mengajar (learned action). Selanjutnya dijelaskan pula bahwa ditinjau secara umum budaya memiliki dua dimensi, yaitu dimensi wujud dan isi. Dalam dimensi wujud, budaya terdiri dari tiga unsur, yaitu: (1) wujud dalam bentuk ide atau gagasan, (2) wujud dalam bentuk aktivitas atau kegiatan, dan (3) wujud dalam bentuk artifak atau benda-benda. Ditinjau dari dimensi isi, kebudayaan terdiri dari tujuh unsur, yaitu: (1) sistem religi, (2) bahasa, (3) teknologi dan peralatan hidup, (4) sistem mata pencaharian, (5) sistem organisasi sosial, (6) pendidikan, dan (7) kesenian.

\section{Sementara itu Koentjoroningrat} sendiri membagi kebudayaan menurut bentuk dan isinya, yaitu: 1. Sistem Kebudayaan (Cultural system), suatu kebudayaan yang berwujud gagasan, pikiran, konsep, nilai nilai budaya, norma norma, pandangan yang bentuknya abstrak 2 . Sistem Sosial (Social System), berwujud aktivitas, tingkah laku berpola, perilaku, upacara serta ritus ritus yang wujudnya lebih konkrit dan dapat diamati. 3. Benda benda budaya (Material Culture), sebagai kebudayaan pisik atau kebudayaan material. Benda budaya merupakan tingkah laku dan karya pemangku kebudayaan (Rakhmat, 2003).

Definisi klasik tentang kebudayaan dijelaskan oleh Sir Edward Tylor (Horton, 1991), yaitu keseluruhan yang kompleks dari pengetahuan, keyakinan, kesenian, moral, hukum, adat istiadat, dan semua kemampuan dan kebiasaan yang lain yang diperoleh oleh seseorang sebagai anggota masyarakat. Bila dinyatakan secara lebih sederhana, kebudayaan adalah segala sesuatu yang dipelajari dan dialami bersama secara sosial oleh para anggota suatu masyarakat. Kebudayaan dapat dibagi ke dalam kebudayaan materi dan nonmateri. Kebudayaan nonmateri terdiri dari kata-kata yang dipergunakan orang, hasil pemikiran, adat istiadat, keyakinan yang mereka anut, dan kebiasaan yang mereka ikuti. Kebudayaan materi terdiri dari benda-benda hasil pabrik, misalnya alat-alat, mebel, mobil, bangunan, irigasi, parit, lading yang diolah, jalan, jembatan, dan segala benda fisik yang telah diubah dan dipakai orang.

Para ahli juga ada yang membedakan antara kata kebudayaan/culture (Bahasa Inggris) dengan kata peradaban/ civilization (Bahasa Perancis). Seperti Malinowsky dalam Muji Sutrisno mengartikan kata civilization sebagai aspek khusus dari kebudayaan yang lebih maju. J. Maritin lebih menekankan aspek rasional dan moral pada arti kata kebudayaan, dan aspek sosial, 
politik, dan institusional pada kata peradaban.

Pemahaman terhadap definisi atau pengertian kebudayaan penting dilakukan sebagai dasar analisis pemikiran Ali Ahmad Madkur tentang kebudayaan dalam pandangan Islam. Sebab aspek-aspek yang membangun pengertian kebudayaan menjadi bagian penting dari penjelasan beliau tentang bagaimana Islam memandang kebudayaan dengan berbagai karakteristiknya. Budaya Islam sebagai sistem nilai budaya sangat relevan dijadikan sebagai sistem nilai budaya global. Mengingat sistem sistem nilai budaya merupakan bagian dari kebudayaan, maka budaya Islam akan menjadi pengarah dan pendorong yang positif bagi masyarakat manusia.

Koentjaraningrat (Koentjaraningrat, 1993) berpendapat bahwa sistem nilai budaya yang cocok untuk pembangunan manusia meliputi paling sedikit lima konsep. Pertama, dalam menghadapi hidup orang harus menilai tinggi unsur-unsur yang menggembirakan dari hidup; dan bahwa ada kesengsaraan, bencana, dosa, dan keburukan dalam hidup memang harus disadari, tetapi hal itu semuanya adalah untuk diperbaiki. Demikianlah sikap yang aktif dan bukan sikap yang pasif, serta bukan pula fatalistis terhadap hidup yang harus dinilai tinggi sebagai perngarah tindakan yang utama. Kedua, sebagai dorongan dari semua karya manusia agar lebih banyak lagi menghasilkan karya yang bermanfaat. Ketiga, dalam hal menanggapi alam, orang harus memiliki keinginan untuk menguasai alam serta kaidah-kaidahnya. Keempat, dalam segala aktivitas hidup orang harus dapat sebanyak mungkin berorientasi ke masa depan. Kelima, dalam membuat keputusan-keputusan seseorang harus bisa berorientasi ke sesamanya, menilai tinggi kerja sama dengan orang lain, tanpa meremehkan kualitas individu dan tanpa menghindari tanggung jawab sendiri.

Sistem nilai budaya sebagaimana dijelaskan Koentjaraningrat tersebut sangat relevan dengan karakteristik budaya dalam pandangan Islam berdasarkan pemikiran Ali Ahmad Madkur. Beberapa kalangan ilmuwan maupun budayawan juga telah mengakui hal tersebut. Permusyawaratan ilmiah tentang "cultural relations for the future" (hubungan kebudayaan di kemudian hari) melaporkan tentang "reconstituting the human community" yang kesimpulannya antara lain sebagai berikut: "Untuk menetralkan pengaruh teknologi yang menghilangkan kepribadian, kita harus menggali nilai-nilai keagamaan dan spiritual." (Shihab, 2007) Laporan tersebut sebelumnya telah diungkapkan oleh filosof Muhammad Iqbal, yang ketika itu menyadari dampak negatif perkembangan ilmu dan teknologi. Beliau menulis: "kemanusiaan saat ini membutuhkan tiga hal, yaitu penafsiran spiritual atas individu, dan satu himpunan asas yang dianut secara universal yang akan menjelaskan evolusi masyarakat manusia atas dasar spiritual.

\section{B. METODOLOGI}

Dalam penulisan jurnal ini penulis menggunakan metode studi riset kepustakaan (library research), kemudian dianalisis dengan menggunakan metode analisis isi (content analysis) yakni berupa deskriptif-analitik dengan cara mengumpulkan data dari pustaka yang berhubungan dengan pembahasan buku manhaj al-Tarbiyah fi al-Tashowwuri al-Islami 
mengenai kebudayaan dalam pandangan Islam, diimbangi dengan sumber sekunder lainnya yang berkaitan dengan topik penelitian.

\section{HASIL DAN PEMBAHASAN}

Ali Ahmad Madkur adalah Salah satu tokoh pendidikan Islam kontemporer di Timur Tengah. Beliau lahir di kota Mesir (Qohiroh) pada tanggal 10 April 1941 Gelar sarjana bidang Pendidikan beliau peroleh di Al-azhar University Mesir. Sekarang menjadi guru besar (Profesor) di bidang pengembangan kurikulum pendidikan di Universitas Kairo Mesir. Sebelumnya pada tahun 2001 ia dipercaya sebagai Dekan Fakultas Tarbiyah di Universitas Sultan Qobus Oman. Sebagai seorang Profesor dibidang kurikulum dan pendidikan Ahmad Madkur dikenal aktif memberikan materi seminar ilmiah dalam dan luar negeri yang berkenaan dengan kependidikan dan bahasa di beberapa perguruan tinggi di timur tengah. Sebagai pembicara pada seminar International Language Conference (ILC) pada bulan April 2011 di Kuala Lumpur - Malaysia.Sebagai orang yang aktifdiberbagai seminar Internasional ia juga aktif menulis dalam bidang pendidikan maupun Bahasa Arab. Di antara karya-karya Ali Ahmad Madkur adalah: Tadris Funun AllughahAl-arabiyah, Dar al-Furqan,Kairo, 2002, At Ta'lim Al 'Aliy Fii Al Wathan Al'Arabi(Ali Ahmad Madkur.com ). tt.AlManhaj Al-Madrasi al-Mu'ashir. Dar AlFurqan, Kairo, 2009.Manhaj al-Tarbiyah fi al-Tashawwur al-Islami, Dar al- Fikri alArabi, Kairo, 2002, dan Manahij alTarbiyah: AsasuhawaTathbiqatuha.(Romli, 2019).
Budaya dalam konsepsi Islam menurut Ali Ahmad Madkur didasarkan pada prinsip dasar bahwa Allah Yang Mahaesa dan Mahatinggi yang menjadi landasan kebudayaan. Berdasarkan kaidah ini, beliau menjelaskan bahwa budaya dalam konsepsi Islam memiliki dua bagian penting, yaitu aspek normatif yaitu hukum Tuhan (Kitab Allah dan sunnah Rasululullah) dan aspek penerapan, yaitu amal perbuatan yang benar sesuai aspek normatif. Adapun hukum Tuhan yang dimaksud adalah semua yang sudah Allah Swt. tetapkan untuk mengatur kehidupan manusia. Hal terpenting yang mewakili aspek ini adalah sebagaimana yang dinyatakan oelh al-ustadz Sayyid Qutb sebagai berikut.

1. Dasar-dasar keyakinan, seperti persepsi tentang realitas keilahian dan realitas alam semesta, misalnya peristiwa okultasi (contohnya gerhana matahari atau bulan) serta bagaimana manusia meyakini kebenaran bahwa realitas tersebut merupakan wujud keagungan Tuhan.

2. Aset pemerintahan, contohnya kondisi politik, sosial, dan ekonomi, serta perinsip yang menjadi dasarnya, yaitu pengabdian kepada Tuhan.

3. Dasar-dasar moral dan perilaku, berupa standar nilai dan standar norma yang berlaku di masyarakat, dilaksanakan dalam kehidupan sehari-hari.

4. Dasar-dasar pengetahuan, yaitu landasan dalam bidang intelektual, Pendidikan, seni, dan aktivitas sastra.

Keempat hal penting tersebut merupakan komponen hukum Islam secara keseluruhan yang merepresentasikan bagian normatif dari kebudayaan dalam persepekif (pandangan) Islam. 
Sisi lain dari kebudayaan berdasarkan pandangan Islam adalah aspek terapan, dalam arti implementasi praktis dari aspek normatif dalam kehidupan. Dengan kata lain, seluruh pola perasaan, pemikiran, perkataan, dan tindakan atau perilaku yang muncul merupakan wujud aspek normatif (hukum Tuhan) tersebut. Dengan demikian, semua prinsip, hukum, dan peraturan perundangundangan yang bertentangan dengan hukum/syariat Islam tidak dianggap sebagai bagian dari budaya Islam. Demikian pula semua adat istiadat, tradisi, pola berpikir, perilaku dan tindakan yang umum dalam masyarakat Islam namun berbeda atau bertentangan dengan prinsip hukum/ syariat, tidaklah dianggap sebagai komponen budaya Islam dan samasekali tidak terkait dengannya.

\section{Karakteristik budaya Islam}

Budaya Islam dalam pengertian ini adalah budaya ketuhanan yang tergantung pada Syariah, yang direpresentasikan dalam kitab Allah dan Rasul-Nya. Dalam sudut pandang ini, budaya yang dimaksud adalah budaya manusia secara global, tanpa dibatasi oleh sekat-sekat geofrafis, peta politik, atau batas-batas bumi lainnya.

Budaya Islam meliputi aspek Syariah sebagai aspek mutlak dan mengikat dan praktiknya dalam kehidupan menegaskan adanya hubungan permanen antara seorang muslim dengan Tuhannya. Hubungan tersebut juga menunjukkan sikap penghambaan seorang muslim kepada Allah Swt. Budaya Islam merupakan budaya yang adil dan bersifat universal, bukan sebatas lokal, nasional atau regional. Hal ini ditunjukkan dengan kebencian Islam terhadap monopoli, eksploitasi, dan ketidakadilan, kapan pun, di mana pun, dan oleh siapa pun, bahkan jika perilaku tersebut ditunjukkan oleh seorang nabi. Penegasan hal ini dinyatakan dalam Q.S. Shad (38) ayat 26 berikut.

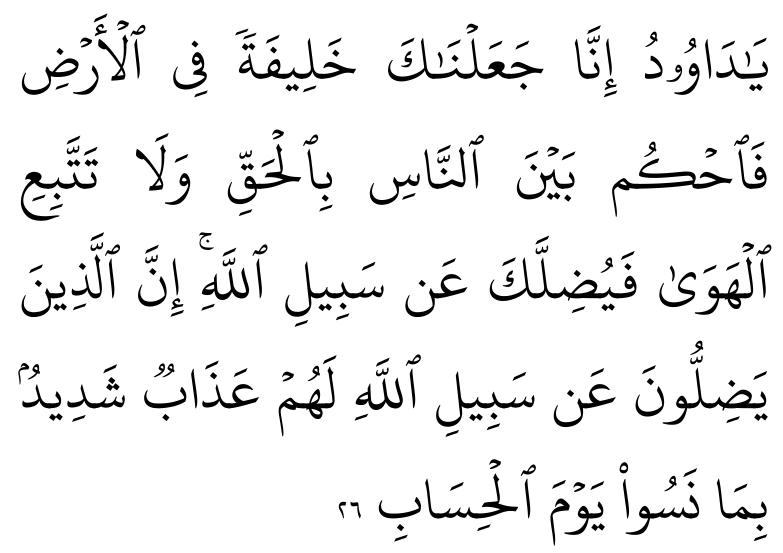

"Hai Daud, sesungguhnya Kami menjadikan kamu khalifah (penguasa) di muka bumi, maka berilah keputusan (perkara) di antara manusia dengan adil dan janganlah kamu mengikuti hawa nafsu, karena ia akan menyesatkan kamu dari jalan Allah. Sesungguhnya orang-orang yang sesat darin jalan Allah akan mendapat azab yang berat, karena mereka melupakan hari perhitungan"

Pandangan Islam tersebut
membuktikan pentingnya keseimbangan antara kebutuhan spiritual dengan kebutuhan material dan sosial. Al-Ustadz Muhammad Asad menyatakan bahwa suatu budaya yang tidak dapat membangun keseimbangan antara kebutuhan fisik dan sosial serta kerinduan spiritual bagaimanapun tidak akan mampu menolong seseorang dari akibat buruk perkembangan zaman. Budaya yang tidak memiliki keseimbangan tersebut bahkan akan menyebabkan hilangnya tujuan hidup yang sebenarnya.

Kebudayaan Islam memiliki karakteristik yang berbeda dengan budaya barat, bahkan budaya manusia pada umumnya sekarang, yang oleh beberapa sarjana barat dijelaskan sebagai budaya 
kelompok. Definisi budaya yang dimaksud mencakup semua jenis pemikiran, tindakan, kognitif, emosi, dan perilaku sebagai cara berpikir kelompok. Dalam budaya kelompok semacam ini, tidak ada komitmen antarkelompok karena sifatnya yang nasional, regional, dan populis. Akan tetapi antarbudaya kelompok ini akan saling mempengaruhi bahkan dapat memaksakan masuknya budaya pada suatu kelompok melalui berbagai media, seperti iklan, kurikulum Pendidikan, dan institusi politik, ekonomi, dan sosial.

Berikut adalah perbedaan antara karakteristik budaya Islam dengan budaya lain (budaya barat dan atau budaya sekarang).

Tabel perbedaan antara karakteristik budaya Islam dengan budaya lain (budaya barat dan atau budaya sekarang).

\begin{tabular}{|l|l|l|l|}
\hline \multicolumn{2}{|c|}{$\begin{array}{l}\text { Karakteristik } \\
\text { Budaya Lain }\end{array}$} & \multicolumn{2}{|c|}{$\begin{array}{l}\text { Karakteristik } \\
\text { Budaya Islam }\end{array}$} \\
\hline 1 & $\begin{array}{l}\text { Kemanusiaan: } \\
\text { berasal dari } \\
\text { filosofi dan teori } \\
\text { positivis }\end{array}$ & 1 & $\begin{array}{l}\text { Rabbaniyah: } \\
\text { sumbernya } \\
\text { adalah Al- } \\
\text { Qur'an dan } \\
\text { sunnah }\end{array}$ \\
\hline 2 & $\begin{array}{l}\text { Nasionalisme, } \\
\text { regionalisme, dan } \\
\text { popusilme }\end{array}$ & 2 & $\begin{array}{l}\text { Universal, } \\
\text { manusiawi }\end{array}$ \\
\hline 3 & $\begin{array}{l}\text { Aspek } \\
\text { normatifnya } \\
\text { relatif bervariasi, } \\
\text { dan aspek } \\
\text { implementasinya } \\
\text { selalu berubah, } \\
\text { tidak mutlak } \\
\text { berkomitmen } \\
\text { pada aspek } \\
\text { normatif }\end{array}$ \\
\hline 4 & $\begin{array}{l}\text { Tidak ad } \\
\text { Batasan pada }\end{array}$ & $\begin{array}{l}\text { Aspek } \\
\text { normatif } \\
\text { mutlak harus } \\
\text { dilaksanakan } \\
\text { pada praktik } \\
\text { kehidupan }\end{array}$ \\
\hline
\end{tabular}

\begin{tabular}{|c|c|c|c|}
\hline & $\begin{array}{l}\text { bentuk dan citra } \\
\text { budaya jika tidak } \\
\text { ada standar dan } \\
\text { nilai manusia } \\
\text { yang } \\
\text { membimbing } \\
\text { mereka. }\end{array}$ & & $\begin{array}{l}\text { harus berubah } \\
\text { dan } \\
\text { berkembang, } \\
\text { namun wajib } \\
\text { berpedoman } \\
\text { pada aspek } \\
\text { normatif }\end{array}$ \\
\hline 5 & $\begin{array}{l}\text { Penghambaan } \\
\text { hamba kepada } \\
\text { hamba }\end{array}$ & 5 & $\begin{array}{l}\text { Membangun } \\
\text { hubungan } \\
\text { permanen } \\
\text { antara manusia } \\
\text { dengan Tuhan, } \\
\text { dalam bentuk } \\
\text { penghambaan } \\
\text { makhluk } \\
\text { terhadap } \\
\text { Tuhannya }\end{array}$ \\
\hline 6 & $\begin{array}{l}\text { Budaya } \\
\text { dipaksakan oleh } \\
\text { oleh kelas/ } \\
\text { kelompok } \\
\text { ekonomi dan } \\
\text { politik yang } \\
\text { mendominasi }\end{array}$ & 6 & $\begin{array}{l}\text { Budaya } \\
\text { merdeka, } \\
\text { membebaskan } \\
\text { manusia dari } \\
\text { perbudakan } \\
\text { kepada } \\
\text { manusia lain }\end{array}$ \\
\hline 7 & $\begin{array}{l}\text { Kurangnya } \\
\text { keseimbangan }\end{array}$ & 7 & $\begin{array}{l}\text { Budaya yang } \\
\text { seimbang, } \\
\text { antara ruh dan } \\
\text { materi }\end{array}$ \\
\hline 8 & $\begin{array}{l}\text { Budaya manusia } \\
\text { yang cenderung } \\
\text { pada monopoli, } \\
\text { eksploitasi, dan } \\
\text { ketidakadilan }\end{array}$ & 8 & $\begin{array}{l}\text { Budaya } \\
\text { ketuhanan, } \\
\text { yang adil dan } \\
\text { universal oleh } \\
\text { karena itu } \\
\text { membenci } \\
\text { monopoli, } \\
\text { eksploitasi, } \\
\text { dan } \\
\text { ketidakadilan. }\end{array}$ \\
\hline
\end{tabular}

2. Perubahan Budaya dalam pandangan Islam 
Perubahan budaya dalam masyarakat seiring perkembangan zaman juga menjadi bagian dari pembahasan budaya Islam oleh Ali Ahmad Madkur. Perubahan tersebut terjadi berdasarkan pada dua landasan penting. Pertama, bahwa budaya merupakan warisan manusia yang memiliki keterikatan dengan tanah air, jenis kelamin, dan agama. Kedua, persepsi Islam terhadap budaya tidak terlepas dari eksistensi ilmu pengetahuan yang diakui sangat terkait dengan segala aktivitas manusia, nilai-nilai, prioritas, dan adat kebiasaan.

Dalam pandangan Islam,perubahan budaya dapat terjadi di dalam budaya itu sendiri. yang disebabkan oleh adanya pengaruh dari budaya lain. Dalam hal ini, budaya Islam menerima variabel perubahan terkait ilmu dan pengetahuan. Namun budaya Islam bersikap berhati-hati terhadap perubahan yang disebabkan budaya lain yang bertentangan dengan aspek normatif dari budaya Islam. Budaya Islam adalah budaya ketuhanan. Oleh karena itu, bersifat manusiawi dan universal yang meliputi seluruh manusia di bumi. Budaya Islam menjamin pertumbuhan dan perkembangan manusia. Sejarah menunjukkan bahwa peradaban industri di Eropa berasal dari budaya dan peradaban Islam. Prevolt dalam bukunya "Making Humanity" menjelasakn bahwa orang-orang Eropa telah mempelajari begitu banyak ilmu pengetahuan yang menunjang kemampuan keilmuan mereka dan mendorong munculnya penemuanpenemuan yang inovatif. Namun demikian, aspek penting dari budaya Islam yang mereka adopsi ternyata dihilangkan, yaitu aspek normatif dalam budaya Islam. Oleh karena itu, produk budaya Eropa secara keseluruhan menjadi sesuatuyang lain dan berbeda dengan produk budaya Islam.

Perubahan dalam kebudayaan Islam juga terjadi sebagai suatu keniscayaan, khususnya pada aspek terapan dan produk budaya. Proses perubahan budaya Islam dalam hal kuantitas dan kualitasnya ditentukan oleh kadar ketaatan masyarakat terhadap nilai dan prinsip yang mereka yakini. Masyarakat Islam terikat dengan seperangkat sistem nilai dan norma ketuhanan yang tidak ikut berubah. Namun tetap mendorong kea rah perubahan yang sesuai dengan fitrah kemanusiaan.

Ali Ahmad Madkur juga menyoroti perihal perubahan budaya Islam dalam konteks Pendidikan. Bahwa hakikatnya seluruh proses dalam pendidikan selalu mengacu berdasarkan kurikulum, sedangkan kurikulum pendidikan Islam itu adalah aturan dan nilai-nilai kebenaran Tuhan, pengetahuan dan pengalaman serta keterampilan manusia yang dinamis dan dirancang oleh lembaga pendidikan Islam untuk disajikan kepada peserta didik dengan tujuan mengantarkan mereka kepada level kesempurnaan. yang dimaksud level kesempurnaan yaitu tingkatan yang telah dianugrahkan Tuhan kepada mereka sehingga dengan hal itu mereka dapat melaksanakan tugas khalifah di muka bumi yang sesuai dengan aturan Allah. Oleh karena itu, aspek normatif dalam kurikulum tidak boleh berubah, yaitu nilai-nilai kebenaran Tuhan,yang disampaikan melalui Al-Qur'an dan sunnah.

3. Budaya Islam sebagai sistem nilai budaya dalam masyarakat Global 
Kebudayaan Islam merupakan suatu sistem yang memiliki sifat-sifat ideal, sempurna, praktis, aktual, diakui keberadaannya dan senantiasa diekspresikan. Sistem yang ideal berdasarkan pada hal-hal yang biasa terjadi dan berkaitan dengan yang aktual (Picktchall, 1993). Sistem Islam menerapkan dan menjanjikan perdamaian dan stabilitas di manapun manusia berada, karena pada hakikatnya manusia memiliki kedudukan yang sama di hadapan Allah SWT, yang berbeda justru hanya terletak pada unsur-unsur keimanan dan ketakwaannya saja.

Tajamnya perbedaan antara budaya dalam pandangan Islam (selanjutnya ditulis sebagai budaya Islam) dengan budaya barat atau budaya manusia pada zaman sekarang berdasarkan pemikiran Ali Ahmad Madkur, menunjukkan besarnya pengaruh kedua budaya tersebut dalam masyarakat. Analisis pengaruh budaya tersebut diawali dengan pemahaman terhadap definisi kebudayaan dari Claude Kluckhohn yang menjelaskan dua unsur pembentuk budaya yaitu dimensi wujud dan isi. Dalam hal ini, dimensi isi yang terdiri dari sistem religi, Bahasa, teknologi dan peralatan hidup, sistem mata pencaharian, sistem organisasi sosial, pendidikan, dan kesenian akan menentukan lahirnya dimensi wujud dalam kebudayaan, yaitu ide atau gagasan, aktivitas atau kegiatan, dan artifak atau benda-benda yang dihasilkan.

Kebudayaan yang bersifat materi (dimensi wujud) selalu merupakan hasil perkembangan kebudayaan nonmateri (dimensi isi) dan tidak ada artinya tanpa kebudayaan nonmateri (Horton, 1991). Selaras dengan pemikiran Ali Ahmad
Madkur bahwa kebudayaan dalam pandangan Islam memiliki dua bagian penting, yaitu aspek normatif yaitu hukum Tuhan (Kitab Allah dan sunnah Rasulullah) dan aspek penerapan, yaitu amal perbuatan yang benar sesuai aspek normatif. Maka dimensi isi/ nonmateri yang dimaksud adalah aspek normatif dan dimensi wujud/ materi adalah aspek penerapan atau amal perbuatan yang benar sesuai aspek normatif.

Mengingat kebudayaan menyangkut aturan yang harus diikuti, dapat dikatakan bahwa kebudayaan bersifat normatif, dengan kata lain kebudayaan akan menentukan standar perilaku. Realitas yang berlaku sekarang menunjukkan perilaku individu dan masyarakat yang tidak lagi memperhatikan kemaslahatan lingkungan dan ketinggian moral. Telah sejak lama bumi tempat umat manusia hidup menderita berbagai kerusakan fisik. Sejak dimulainya revolusi industri di Inggris lebih dari serratus tahun lampau. Negara-negara yang melakukan industrialisasi telah banyak mencemarkan udara hingga hari ini. Penghancuran hutanhutan yang amat luas di seluruh dunia dalam berbagai bentuk telah mempertinggi tingkat kerusakan alam dan lingkungan hidup di bumi. Di tingkat nasional maupun internasional, antara bangsa-bangsa semakin nampak ketimpangan dan ketidakadilan. Masyarakat seolah terbagi dalam kelompokkelompok kelas sosial yang berbeda-beda. Kaitannya dengan moral dan tata kelakuan yang berlaku di masyarakat sekarang sangat jelas terjadi penurunan. Masyarakat tidak lagi memandang penting aspek nilai moral dan norma, baik norma agama, kesusilaan, kesopanan, maupun norma hukum. Kenyataan tersebut menjadi bukti dominasi 
budaya barat, sebagaimana telah dijelaskan ciri-ciri/ karakteristiknya oleh Ali Ahmad Madkur.

Guna menyelamatkan bumi dan masyarakat manusia selanjutnya, diperlukan nilai-nilai budaya baru yang mengandung etika global. (Mochtar Lubis dalam Tuhuleley, 1993). Untuk dapat mengembangkan budaya baru ini, perlu dikembangkan kearifan dan kesadaran baru, antara lain:

1. Kesadaran bahwa bumi ini dan segala isinya harus dikelola dengan penuh tanggung jawab agar dapat memberikan manfaat bagi masyarakat sekarang dan yang akan datang.

2. Nilai etika global yang kedua adalah rasa tanggung jawab terhadap seluruh masyarakat manusia dalam mengembangkan teknologi. Mempertimbangkan dampaknya terhadap lingkungan hidup dan manusia.

3. Nilai etika global yang ketiga adalah nilai keadilan secara global, tidak ada lagi dominasi kelas-kelas sosial yang berbeda.

Memperhatikan ketiga budaya global yang dipandang mampu mengatasi kerusakan lingkungan dan moral masyarakat tersebut ternyata sesuai dengan karaketristik budaya Islam sebagaimana dijelaskan Ali Ahmad Madkur, yaitu aspek normatif (syariat Islam). Budaya Islam adalah budaya ketuhanan yang tergantung pada Syariah, yang direpresentasikan dalam kitab Allah dan Rasul-Nya. Dalam sudut pandang ini, budaya yang dimaksud adalah budaya manusia secara global, tanpa dibatasi oleh sekat-sekat geofrafis, peta politik, atau batas-batas bumi lainnya. Dengan demikian, manusia akan berperilaku atas dasar kemaslahatan bagi masyarakat seluruhnya di dunia. Dalam syariat Islam terlarang manusia berbuat kerusakan di muka bumi, sebagaimana dinyatakan dalam Q.S. Al-Baqarah (2) ayat 11.

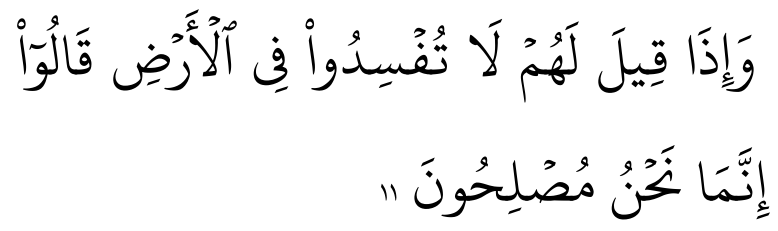

"Dan bila dikatakan kepada mereka: "Janganlah kamu membuat kerusakan di muka bumi". Mereka menjawab: "Sesungguhnya kami orang-orang yang mengadakan perbaikan"

Islam juga mengajarkan keadilan,antara lain dinyatakan dalam Q.S. An-Nisa (4) ayat 58.
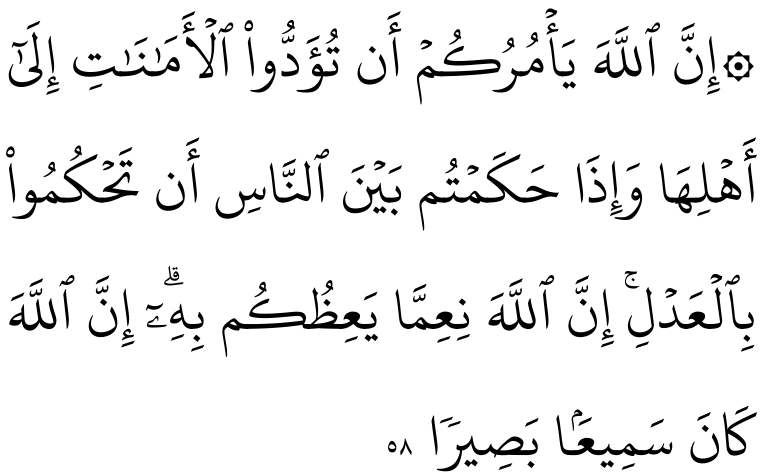

"Sesungguhnya Allah menyuruh kamu menyampaikan amanat kepada yang berhak menerimanya, dan (menyuruh kamu) apabila menetapkan hukum di antara manusia supaya kamu menetapkan dengan adil. Sesungguhnya Allah memberi pengajaran yang sebaik-baiknya kepadamu. Sesungguhnya Allah adalah Maha Mendengar lagi Maha Melihat".

Budaya Islam sebagai sistem nilai budaya dalam masyarakat diyakini dapat menjadi solusi bagi berbagai masalah dalam masyarakat selain kerusakan lingkungan dan 
ketidakadilan sebagaimana dijelaskan sebelumnya. Faktor sikap mental disebut sebagai salah satu faktor penghambat pembangunan. Mentalitas pembangunan adalah suatu syarat nilai budaya yang berorientasi ke masa depan, suatu sifat hemat, suatu hasrat untuk bereksplorasi dan berinovasi, suatu pandangan hidup yang menilai tinggi achievement dari karya, suatu nilai budaya yang berorientasi ke masa depan, suatu sikap percaya pada kemampuan sendiri, berdisiplin, dan bertanggung jawab. Berbagai permasalahan yang terjadi di berbagai negara kaitannya dengan pembangunan dipengaruhi oleh menurunnya kualitas mentalitas pembangunan masyarakatnya. Usaha untuk mengubah dan membina mentalitas baru harus dijalankan secara simultan dengan usaha pembangunan itu sendiri, sehingga menjadi suatu usaha penunjang pembangunan yang penting. (Lumintang, 2015).

Kata sikap mental juga dikenal sebagai istilah populer untuk dua konsep yang dengan istilah ilmiah disebut "sistem nilai-budaya" (cultural value system) dan "sikap" (attitude). Adapun yang dimaksud dengan sistem nilai budaya adalah suatu rangkaian dari konsep abstrak yang hidup dalam alam pikiran Sebagian besar dari warga suatu masyarakat, mengenai apa yang harus dianggap penting dalam berharga dalam hidupnya (Koentjaraningrat, 1993). Dengan demikian, suatu sistem nilai budaya biasanya merupakan bagian dari kebudayaan yang berfungsi sebagai pengarah dan pendorong kelakuan manusia. Sistem nilai budaya tersebut berupa konsep-konsep yang abstrak, diterima, dan diyakini oleh masyarakat, sehingga lebih mandarah daging, dan permanen. Bila sistem nilai budaya itu merupakan pengarah bagi perilaku manusia, maka sistem nilai tersebut hendaknya mampu menumbuhkan dan memperkuat mentalitas yang mendukung pembangunan dan kemajuan masyarakat.

Aspek normatif budaya Islam yang dijelaskan Ali Ahmad Madkur menunjukkan sumber kebudayaan Rabbaniyah yaitu AlQur'an dan sunnah sebagai sistem nilai yang berlaku bagi masyarakat muslim. Betapa banyak ayat dalam Al-Qur'an yang mengajarkan pentingnya melakukan perbuatan baik dan secara tidak langsung akan mampu memelihara sikap mental manusia. Ayat Qur'an tersebut antara lain Q.S. An-Nisa (4) ayat $122-123$
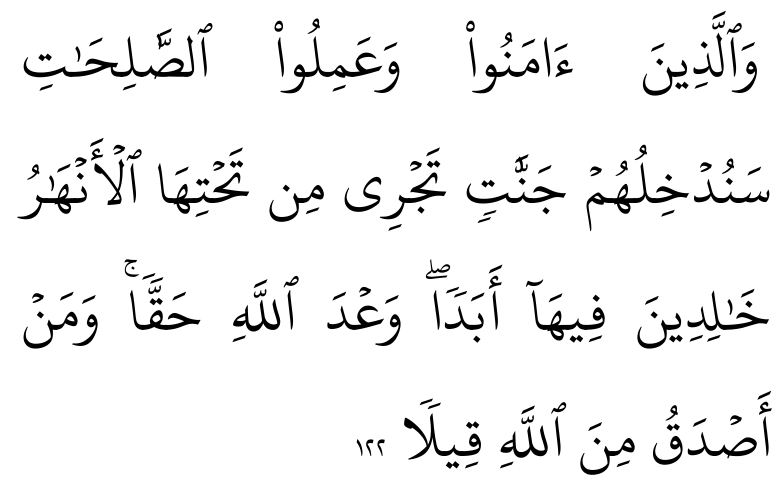

"Orang-orang yang beriman dan mengerjakan amalan saleh, kelak akan Kami masukkan ke dalam surga yang mengalir sungai-sungai di dalamnya, mereka kekal di dalamnya selama-lamanya. Allah telah membuat suatu janji yang benar. Dan siapakah yang lebih benar perkataannya dari pada Allah" 

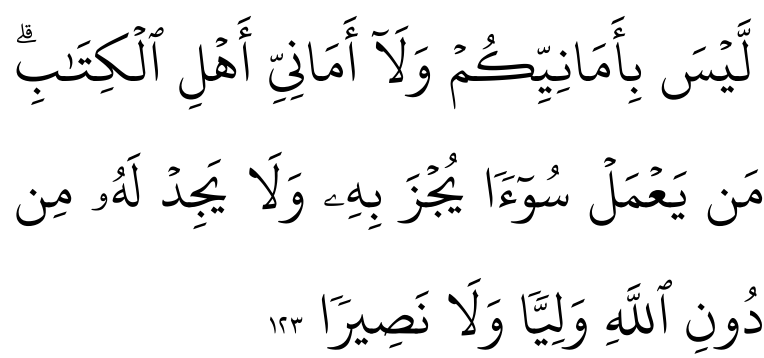

"(Pahala dari Allah) itu bukanlah

menurut angan-anganmu yang kosong dan tidak (pula) menurut angan-angan Ahli Kitab. Barangsiapa yang mengerjakan kejahatan, niscaya akan diberi pembalasan dengan kejahatan itu dan ia tidak mendapat pelindung dan tidak (pula) penolong baginya selain dari Allah"

Nilai-nilai yang terkandung dalam aspek normatif/ ketuhanan dalam budaya Islam dapat mewarnai kehidupan masyarakat tanpa dibatasi oleh sekat-sekat geografis, sebagaimana pemikiran Ali Ahmad Madkur sehingga dapat berlaku secara global. Aspek normatif dalam budaya Islam tersebut berupa syariat dan ajaran Allah Swt.

\section{KESIMPULAN}

Budaya dalam konsepsi Islam menurut Ali Ahmad Madkur memiliki dua bagian penting, yaitu aspek normatif yaitu hukum Tuhan (Kitab Allah dan sunnah Rasululullah) dan aspek penerapan, yaitu amal perbuatan yang benar sesuai aspek normatif. Budaya Islam meliputi aspek Syariah sebagai aspek mutlak dan mengikat dan praktiknya dalam kehidupan menegaskan adanya hubungan permanen antara seorang muslim dengan Tuhannya. Hubungan tersebut juga menunjukkan sikap penghambaan seorang muslim kepada Allah Swt. Budaya Islam merupakan budaya yang adil dan bersifat universal, bukan sebatas lokal, nasional atau regional. Budaya Islam sebagai sistem nilai budaya dalam masyarakat diyakini dapat menjadi solusi bagi berbagai masalah dalam masyarakat selain kerusakan lingkungan dan ketidakadilan. Budaya Islam sebagai sistem nilai budaya memiliki karakteristik yang bersifat global dan diperlukan dalam kondisi masyarakat dunia saat ini.

\section{DAFTAR PUSTAKA}

Horton, Paul B. dan Chester L. Hunt, 1991. Sosiologi, Penerbit Erlangga: Jakarta.

Koentjaraningrat, 1980. Pengantar Ilmu Antropologi. Jakarta: Perwira.

Koentjaraningrat, 1993. Manusia Dan Kebudayaan Di Indonesia, Penerbit Djambatan: Jakarta.

Lumintang, Juliana, 2015. Pengaruh Perubahan Sosial Terhadap Kemajuan Pembangunan Masyarakat Di Desa Tara-Tara I.

Madkur ,Ali Ahmad, Manhaj al-Tarbiyah fi al-Tashowwuri al-Islami, Saudi Arabi, Darul Fikri al-Arobi, 2002.

Picktchall, Muhammad Marmaduke, 1993, Kebudayaan Islam, Penerbit PT. Bungkul Indah, Surabaya.

Rakhmat, Jalaluddin, 2009. Psikologi Agama, PT Raja Graafindo Prsada, Jakarta

Romli, Moh, 2019. Metode Pembelajaran Sebagai Rekonstruksi Karakter Siswa;

Persfektif Pemikiran Ali Ahmad Madkur, Journal.Laaroiba.Ac.Id/Index.Php/Jdi/A rticle.

Shihab, M. Quraish, 2007. Membumikan AlQur'an, Mizan: Bandung.

Sutrisno, Mudji, 2008. Filsafat Kebudayaan Ihtiar Sebuah Teks, Hujan Kabisat: Jakarta.

Tuhuleley, Said. 1993.Permasalahan Abad XXI Sebuah Agenda, SIPRESS: Yogyakarta. 
https://ejournal.unsrat.ac.id/index.php/actadiurna komunikasi/article/view/7256/6759. 